\title{
Crystallization and preliminary diffraction analysis of the phosphatase domain of PTPN14 in the human papillomavirus E7 binding-defective mutant form
}

\author{
Dahwan Lim ${ }^{1,2}$, Chang Hoon Lee ${ }^{3}$, Ho-Chul Shin ${ }^{1}$, Seung Jun Kim ${ }^{1, *}$ and Bonsu Ku, ${ }^{1, *}$ \\ ${ }^{1}$ Disease Target Structure Research Center, Korea Research Institute of Bioscience and Biotechnology, Daejeon 34141, Republic of Korea \\ ${ }^{2}$ Department of Biochemistry, Chungnam National University, Daejeon 34134, Republic of Korea \\ ${ }^{3}$ Center for Information-Based Drug Research, Korea Research Institute of Chemical Technology, Daejeon 34114, Republic of Korea \\ *Correspondence: ksj@kribb.re.kr, bku@kribb.re.kr
}

A tumor suppressor protein PTPN14 interacts with the oncoprotein E7 of human papillomaviruses, leading to its proteasomal degradation. Introduction of F1044S, G1055Q, and E1095A mutations into its phosphatase domain restored the antitumor activity by impairing the interaction with E7, showing the therapeutic potential of this mutant form against human papillomavirus-involved cancers. In this study, the phosphatase domain of PTPN14 containing the three mutations was produced in an Escherichia coli expression system, purified using Ni-NTA affinity and size exclusion chromatographies, and then crystallized. X-ray diffraction data with a maximum resolution of $1.50 \AA$ were successfully collected, and a preliminary diffraction analysis was conducted. Our crystals belonged to the $P 2_{1}$ space group with unit cell parameters of $a=43.9 \AA, b=74.3 \AA, c=47.8 \AA$, and $\beta=102.0^{\circ}$. The asymmetric unit contains one protein molecule with a $45 \%$ solvent content and a $2.2 \AA^{3} / \mathrm{Da}$ Matthews coefficient.

\section{INTRODUCTION}

Classical protein tyrosine phosphatases (PTPs), which catalyze the removal of a phosphate group from phosphorylated tyrosine residues, can be divided into receptor-type PTPs localized to the plasma membrane and nonreceptor-type PTPs that reside in the cytoplasm (Tonks, 2006; Lee et al., 2015). PTPN14, also called PTP-Pez, PTP36, or PTPD2, is a nonreceptor-type PTP. PTPN14 functions as a key regulator of the Hippo signaling pathway (Mello et al., 2017), one of the central cascades controlling cellular proliferation and apoptosis, and is intimately associated with tumorigenesis (Saucedo and Edgar, 2007; Meng et al., 2016). Numerous studies have indicated that PTPN14 is an important tumor suppressor as it inhibits the oncogenic activity of yesassociated protein, the core downstream effector of the Hippo cascade (Wang et al., 2012; Huang et al., 2013; Michaloglou et al., 2013; Wilson et al., 2014). Furthermore, PTPN14 is targeted for proteasome-mediated degradation by the oncoprotein E7 of human papillomaviruses, the causative agents of cervical and other cancers (White et al., 2016; Szalmás et al., 2017). Human papillomavirus E7 recognizes the phosphatase domain of PTPN14 via direct binding; this was structurally determined by $\mathrm{X}$-ray crystallographic and small-angle $\mathrm{X}$-ray scattering analyses (Yun et al., 2019; Lee et al., 2021). The E7 binding-defective mutant PTPN14 was prepared such that Phe1044, Gly1055, and Glu1095 in the phosphatase domain were substituted with serine, glutamine, and alanine, respectively (Yun et al., 2019).
Subsequent biochemical and cellular analyses proved that this mutant is resistant to degradation in HeLa cervical cancer cells and effective in the suppression of cancer cell proliferation, migration, and invasion (Yun et al., 2019). In other words, PTPN14 with F1044S, G1055Q, and E1095A (SQA) mutations was verified as an effective tumor suppressor; therefore, it appears to have therapeutic potential against cervical cancer, one of the most prevalent cancers in women (Bray et al., 2018). In a first step to characterize this mutant protein at the atomic level, we attempted to express, purify, and crystallize the phosphatase domain of the SQA mutant form of PTPN14. We obtained crystals diffracted to $1.50 \AA$ A resolution and conducted a preliminary diffraction analysis.

\section{RESULTS AND DISCUSSION}

The phosphatase domain of human PTPN14 (residues 886-1187) containing F1044S, G1055Q, and E1095A mutations, referred

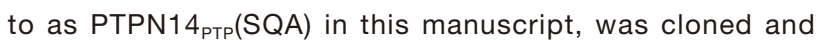
expressed in an Escherichia coli expression system (Table 1). The recombinant PTPN14 PTP $_{(\mathrm{SQA})}$ protein was purified using $\mathrm{Ni}$ NTA affinity and size-exclusion chromatographies. Using the final protein sample, sodium dodecyl sulfate-polyacrylamide gel electrophoresis (SDS-PAGE) was performed to visualize its purity by Coomassie blue staining (Figure 1 ). The protein

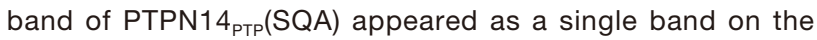
SDS gel, located between the $35 \mathrm{kDa}$ and $43 \mathrm{kDa}$ molecular 
weight standards on the SDS gel (Figure 1), consistent with the calculated molecular weight $(35.2 \mathrm{kDa})$ obtained from the ExPASy server (https://web.expasy.org/cgi-bin/compute_pi/pi_ tool).

After purification, automated screening of protein crystallization conditions was performed using the sitting drop vapor diffusion

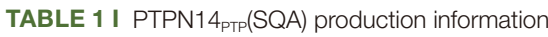

\begin{tabular}{ll}
\hline Source organism & Human \\
\hline DNA source & cDNA \\
\hline Forward primer & CGCGGCAGCCATATGGTTGATGCCACCCGG \\
& GTCCC \\
\hline Reverse primer* & TGCGGCCGCAAGCTITAAATGAGTCTGGAG \\
& TITGGAGGAA \\
\hline Expression vector & pET28a \\
\hline Expression host & E. coli BL21(DE3) RIL \\
\hline & SHMVDATRVPMDERFRTLKKKLEEGMVFTEYE \\
& QIPKKKANGIFSTAALPENAERSRIREWPYEEN \\
& RVELIPTKENNTGYINASHIKVVGGAEWHYIAT \\
Complete amino acid & QGPLPHTCHDFWQMVWEQGVNVIAMVTAEEE \\
sequence of & GGRTKSHRYWPKLGSKHSSATYGKFKVTTKS S \\
the construct produced & RTDSVCYATTQLKVKHLLSGQRTVWHLQYTD \\
& WPDHGCPEDVQGFLSYLEAIQSVRRHTNSML \\
& EGTKNRHPPIVVHCSAGVGRTGVILSELMIYC \\
& LEHNEKVEVPMMLRLLREQRMFMIQTIAQYKFV \\
& YQVLIQFLQNSRLI \\
\hline
\end{tabular}

*Restriction enzyme sites in the primers (Ndel for forward and Hindlll for reverse primers) are underlined.

**The F1044S, G1055Q, and E1095A mutations are marked in red and underlined.

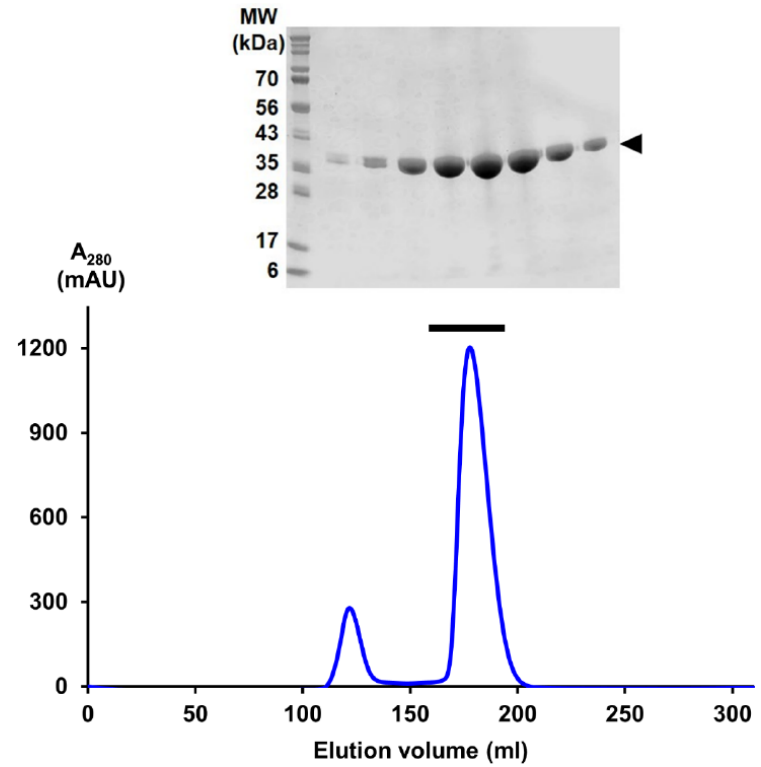

FIGURE 1 I Purified PTPN14 1 PTP (SQA). Recombinant PTPN14 PTP $_{\text {(SQA) }}$

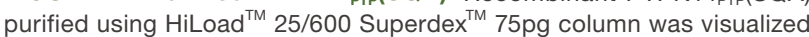
on an SDS gel by Coomassie blue staining. An arrowhead indicates PTPN14 1 PTP $(\mathrm{SQA})$, the calculated molecular weight of which is $35.2 \mathrm{kDa}$. $\mathrm{MW}$, molecular weight marker; $\mathrm{kDa}$, kilodalton; $\mathrm{A}_{280}$, absorbance values at $280 \mathrm{~nm} ; \mathrm{mAU}$, milli absorbance units. method. Initial crystals were obtained using a $40 \mathrm{mg} / \mathrm{ml}$ protein sample in $\mathrm{C} 3$ of a PEG/lon Screen, containing $20 \%$ polyethylene glycol (PEG) 3,350 and $200 \mathrm{mM}$ sodium acetate trihydrate. Crystals were optimized by altering the protein concentration to $30 \mathrm{mg} / \mathrm{ml}$ and the sodium acetate trihydrate concentration in the reservoir solution to $50 \mathrm{mM}$ (Figure 2 and Table 2). X-ray diffraction data to $1.50 \AA$ resolution were collected on beamline $11 \mathrm{C}$ at the Pohang Accelerator Laboratory (PAL; Figure 3) (Park et al., 2017). The space group of PTPN14 PTP $_{(S Q A)}$ crystals was identified as $P 2_{1}$, with unit cell parameters of $a=43.9 \AA$, $b=74.3$ $\AA, \mathrm{c}=47.8 \AA$, and $\beta=102.0^{\circ}$. The total number of reflections was $2,838,848$, merged to 46,882 unique reflections, with a merging $\mathrm{R}$ factor of $5.2 \%$ and a completeness value of $98.0 \%$. The data collection and processing statistics are presented in Table 3. A

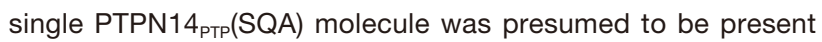
in an asymmetric unit, with the solvent content and Matthews coefficient calculated as $45 \%$ and $2.2 \AA^{3} / \mathrm{Da}$, respectively. Structure determination is currently underway; the molecular replacement method is employed using the phosphatase domain structure of wild-type PTPN14 (PDB code: 2BZL) as a search model.

\section{METHODS}

Preparation of recombinant protein

The fragment containing residues 886-1187 of human PTPN14 (GenBank accession number NP_005392.2) was amplified by
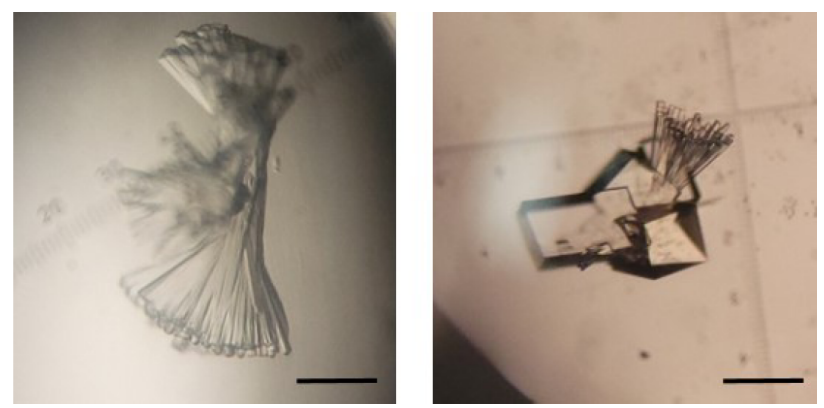

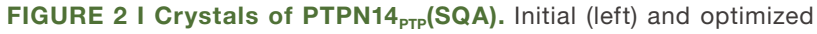
(right) crystals are shown with scale bars indicating $0.1 \mathrm{~mm}$.

TABLE 2 I Crystallization

\begin{tabular}{ll}
\hline Method & Sitting drop vapor diffusion \\
\hline Plate type & 96 -well sitting drop crystallography plate \\
\hline Temperature $(\mathrm{K})$ & 291 \\
\hline Protein concentration $(\mathrm{mg} / \mathrm{ml})$ & 30 \\
\hline $\begin{array}{l}\text { Buffer composition of } \\
\text { protein solution }\end{array}$ & $50 \mathrm{mM} \mathrm{Tris-HCl}(\mathrm{pH} 7.5), 200 \mathrm{mM} \mathrm{NaCl}$, \\
\hline $\begin{array}{l}\text { Composition of } \\
\text { reservoir solution }\end{array}$ & $\begin{array}{l}20 \%(\mathrm{mM} / \mathrm{v}) \text { PEG } 3,350 \text { and } 50 \mathrm{mM} \text { sodium } \\
\text { acetate trihydrate }\end{array}$ \\
\hline Cryoprotectant & $20 \%$ glycerol \\
\hline Volume of drop $(\mu \mathrm{l})$ & $0.4($ protein:reservoir $=1: 1)$ \\
\hline Volume of reservoir $(\mu \mathrm{l})$ & 70
\end{tabular}




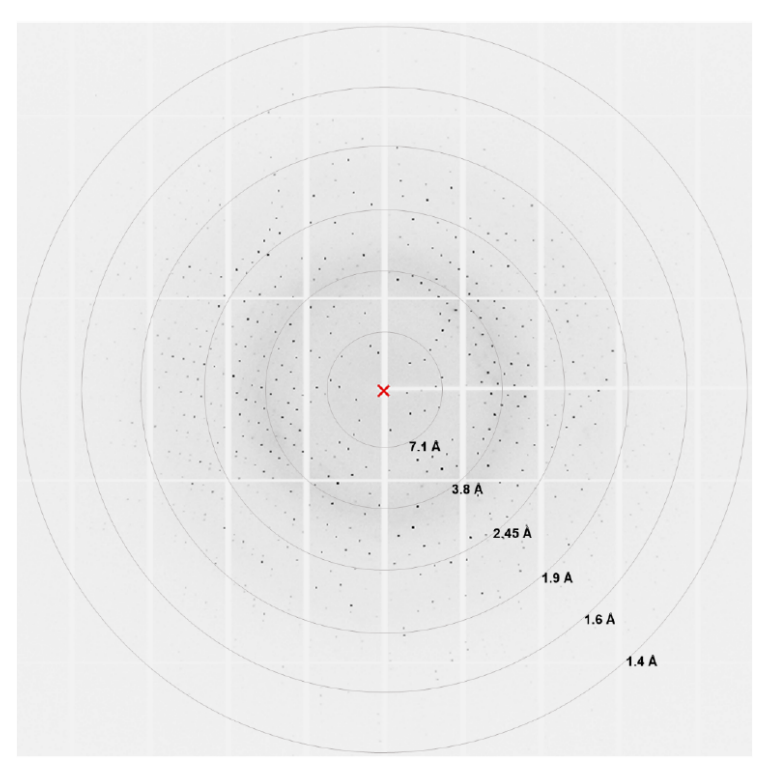

FIGURE 3 I X-ray diffraction image. Representative X-ray diffraction photograph of the PTPN14 ${ }_{\text {PTP }}$ (SQA) crystal with a $1.0^{\circ}$ oscillation range. Circles represent resolution ranges as indicated. The maximum resolution at the edge of the film is $1.4 \AA$.

polymerase chain reaction and cloned into the pET28a plasmid (Novagen) using the forward and reverse primers described in Table 1. It was used as the template to prepare the mutant form of the PTPN14 PTP domain containing F1044S, G1055Q, and E1095A substitutions. The resulting recombinant $\mathrm{pET} 28 \mathrm{a}$ plasmid was transformed into E. coli BL21(DE3) RIL (Novagen) competent cells. The cells were cultured in Luria-Bertani broth at $37^{\circ} \mathrm{C}$ until the optical density at $600 \mathrm{~nm}$ reached 0.6 . Expression of PTPN14 ${ }_{\text {PTP }}(\mathrm{SQA})$ was induced by treatment with $0.5 \mathrm{mM}$ isopropyl- $\beta$-D-thiogalactopyranoside. After incubation at $25^{\circ} \mathrm{C}$ for $16 \mathrm{~h}$, the cells were centrifuged at $1800 \times \mathrm{g}$ for $30 \mathrm{~min}$ at $4^{\circ} \mathrm{C}$ and resuspended in a lysis buffer containing $50 \mathrm{mM}$ Tris- $\mathrm{HCl}$ (pH 7.5), $200 \mathrm{mM} \mathrm{NaCl}$, and $3 \mathrm{mM} \beta$-mercaptoethanol ( $\beta$-ME) for sonication on ice. Cell debris was removed by centrifugation of the cell lysates at $18000 \times g$ for $50 \mathrm{~min}$ at $4^{\circ} \mathrm{C}$. The supernatant was loaded onto Ni-NTA agarose resin (QIAGEN), washed with a wash buffer containing $50 \mathrm{mM}$ Tris- $\mathrm{HCl}(\mathrm{pH} 7.5), 200 \mathrm{mM} \mathrm{NaCl}$, $3 \mathrm{mM} \beta-\mathrm{ME}$, and $30 \mathrm{mM}$ imidazole. A butter solution containing $50 \mathrm{mM}$ Tris ( $\mathrm{pH}$ 7.5), $200 \mathrm{mM} \mathrm{NaCl}, 3 \mathrm{mM} \beta-\mathrm{ME}$, and $300 \mathrm{mM}$ imidazole was used for protein elution. The $\mathrm{N}$-terminal $\mathrm{His}_{6}$-tag was removed by thrombin treatment at $4^{\circ} \mathrm{C}$ for $16 \mathrm{~h}$. The sample was then subjected to a HiLoad ${ }^{\mathrm{TM}}$ 25/600 Superdex ${ }^{\mathrm{TM}} 75 \mathrm{pg}$ column (GE Healthcare) equilibrated with a buffer containing 50 $\mathrm{mM}$ Tris- $\mathrm{HCl}$ (pH 7.5), $200 \mathrm{mM} \mathrm{NaCl}$, and $2 \mathrm{mM}$ dithiothreitol. The purified protein was concentrated to $40 \mathrm{mg} / \mathrm{ml}$ for crystallization.

\section{Crystallization and X-ray data collection}

Protein crystallization conditions were screened using commercial solutions. On day 3 , initial crystals grew under
TABLE 3 I Data collection and processing statistics

\begin{tabular}{ll}
\hline Diffraction source & Beamline 11C, PAL \\
\hline Wavelength $(\AA)$ & 0.9794 \\
\hline Temperature $(\mathrm{K})$ & 100 \\
\hline Space group & $P 2_{1}$ \\
\hline $\mathrm{a}, \mathrm{b}, \mathrm{c}(\AA)$ & $43.9,74.3,47.8$ \\
\hline$\alpha, \beta, \gamma\left({ }^{\circ}\right)$ & $90,102.0,90$ \\
\hline Resolution $(\AA)$ & $50.0-1.5(1.53-1.50)^{\star}$ \\
\hline Total No. of reflections & $2,838,848$ \\
\hline No. of unique reflections & 46,882 \\
\hline Completeness $(\%)$ & $98.0(97.6)$ \\
\hline$R_{\text {merge }}(\%)$ & $5.2(33.0)$ \\
\hline Average $\mathrm{l} / \sigma(\mathrm{l})$ & $27.6(6.2)$ \\
\hline Redundancy & 6.1 \\
\hline
\end{tabular}

*Values in parentheses are for the highest resolution shell.

the C3 condition of the PEG/Ion Screen (Hampton Research), containing $20 \%$ PEG 3,350 and $200 \mathrm{mM}$ sodium acetate trihydrate. Improved crystals were obtained by altering the protein concentration from 40 to $30 \mathrm{mg} / \mathrm{ml}$ and the reservoir solution composition to $20 \%$ PEG 3,350 and $50 \mathrm{mM}$ sodium acetate trihydrate, as described in Table 2. X-ray diffraction data were collected on beamline 11C at PAL (Park et al., 2017) and processed using HKL2000 (Otwinowski and Minor, 1997), as summarized in Table 3.

\section{ACKNOWLEDGEMENTS}

We are grateful to PAL, Korea, for the use of beamline 11C. This work was supported by the National Research Foundation, funded by the Ministry of Science and ICT, Korea (2020R1C1C1008451 and 2019M3E5D6063955) and by the Korea Research Institute of Bioscience and Biotechnology Research Initiative Program (KGM9952112).

\section{CONFLICT OF INTEREST}

The authors declare that there are no conflicts of interest.

Original Submission: Sep 28, 2021

Revised Version Received: Oct 19, 2021

Accepted: Oct 19, 2021

\section{REFERENCES}

Bray, F., Ferlay, J., Soerjomataram, I., Siegel, R.L., Torre, L.A., and Jemal, A. (2018). Global cancer statistics 2018: GLOBOCAN estimates of incidence and mortality worldwide for 36 cancers in 185 countries. $C A$ Cancer J Clin 68, 394-424.

Huang, J.M., Nagatomo, I., Suzuki, E., Mizuno, T., Kumagai, T., Berezov, A., Zhang, H., Karlan, B., Greene, M.I., and Wang, Q. (2013). YAP modifies cancer cell sensitivity to EGFR and survivin inhibitors and is negatively regulated by the non-receptor type protein tyrosine phosphatase 14. Oncogene 32, 2220-2229. 
Lee, H., Yi, J.S., Lawan, A., Min, K., and Bennett, A.M. (2015). Mining the function of protein tyrosine phosphatases in health and disease. Semin Cell Dev Biol 37, 66-72.

Lee, H.S., Kim, M.W., Jin, K.S., Shin, H.C., Kim, W.K., Lee, S.C., Kim, S.J. Lee, E.W., and Ku, B. (2021). Molecular analysis of the interaction between human PTPN21 and the oncoprotein E7 from human papillomavirus genotype 18. Mol Cells 44, 26-37.

Mello, S.S., Valente, L.J., Raj, N., Seoane, J.A., Flowers, B.M., McClendon, J., Bieging-Rolett, K.T., Lee, J., Ivanochko, D., Kozak, M.M., Chang, D.T., Longacre, T.A., Koong, A.C., Arrowsmith, C.H., Kim, S.K., et al. (2017). A p53 super-tumor suppressor reveals a tumor suppressive p53-Ptpn14Yap axis in pancreatic cancer. Cancer Cell 32, 460-473.e466.

Meng, Z., Moroishi, T., and Guan, K.L. (2016). Mechanisms of Hippo pathway regulation. Genes Dev 30, 1-17.

Michaloglou, C., Lehmann, W., Martin, T., Delaunay, C., Hueber, A., Barys, L., Niu, H., Billy, E., Wartmann, M., Ito, M., Wilson, C.J., Digan, M.E., Bauer, A., Voshol, H., Christofori, G., et al. (2013). The tyrosine phosphatase PTPN14 is a negative regulator of YAP activity. PLoS One 8 , e61916.

Otwinowski, Z., and Minor, W. (1997). Processing of X-ray diffraction data collected in oscillation mode. Methods Enzymol 276, 307-326.

Park, S.Y., Ha, S.C., and Kim, Y.G. (2017). The protein crystallography beamlines at the Pohang Light Source II. Biodesign 5, 30-34.
Saucedo, L.J., and Edgar, B.A. (2007). Filling out the Hippo pathway. Nat Rev Mol Cell Biol 8, 613-621.

Szalmás, A., Tomaić, V., Basukala, O., Massimi, P., Mittal, S., Kónya, J., and Banks, L. (2017). The PTPN14 tumor suppressor is a degradation target of human Papillomavirus E7. J Virol 91, e00057-17.

Tonks, N.K. (2006). Protein tyrosine phosphatases: from genes, to function, to disease. Nat Rev Mol Cell Biol 7, 833-846.

Wang, W., Huang, J., Wang, X., Yuan, J., Li, X., Feng, L., Park, J.I., and Chen, J. (2012). PTPN14 is required for the density-dependent control of YAP1. Genes Dev 26, 1959-1971.

White, E.A., Münger, K., and Howley, P.M. (2016). High-risk human papillomavirus E7 proteins target PTPN14 for degradation. mBio 7 , e01530-16

Wilson, K.E., Li, Y.W., Yang, N., Shen, H., Orillion, A.R., and Zhang, J. (2014). PTPN14 forms a complex with Kibra and LATS1 proteins and negatively regulates the YAP oncogenic function. J Biol Chem 289, 23693-23700.

Yun, H.Y., Kim, M.W., Lee, H.S., Kim, W., Shin, J.H., Kim, H., Shin, H.C., Park, H., Oh, B.H., Kim, W.K., Bae, K.H., Lee, S.C., Lee, E.W., Ku, B., and Kim, S.J. (2019). Structural basis for recognition of the tumor suppressor protein PTPN14 by the oncoprotein E7 of human papillomavirus. PLoS Biol 17, e3000367. 